\title{
Maternal risk factors and perinatal outcome in meconium stained amniotic fluid: a cross sectional study
}

\author{
Meera Mohan, Deepak A. V.*
}

Department of Obstetrics and Gynecology, Government Medical College Hospital, Thrissur, Kerala, India

Received: 30 July 2018

Accepted: 29 August 2018

\section{*Correspondence:}

Dr. Deepak A. V.,

E-mail: drdeepakav@gmail.com

Copyright: (C) the author(s), publisher and licensee Medip Academy. This is an open-access article distributed under the terms of the Creative Commons Attribution Non-Commercial License, which permits unrestricted non-commercial use, distribution, and reproduction in any medium, provided the original work is properly cited.

\begin{abstract}
Background: Meconium staining of amniotic fluid has long been regarded as a sign of fetal distress and fetal asphyxia. Although exact cause is unknown, meconium is thought to be passed from fetal gastro-intestinal tract as a response to hypoxia, mesenteric vasoconstriction induced gut hyper peristalsis, vagal stimulation and normal physiologic function of a mature fetus. Overall frequency has ranged from 5 to $24.6 \%$. Present study is undertaken to detect incidence, mode of delivery, fetal heart rate variability and neonatal outcome in neonates born through MSAF. The objective of the study was to maternal risk factors, mode of delivery and perinatal outcome in labors complicated with meconium stained amniotic fluid.

Methods: This is a cross sectional study done at Government Medical College, Thrissur on term, singleton pregnancies complicated with meconium stained amniotic fluid satisfying the inclusion criteria. Patients detailed history, gestational age, per abdominal examination, per speculum and per vaginal examination, admission tests including intrapartum cardiotocography (CTG) was recorded in a predesigned proforma.

Results: The age of the patients varied between above 19 and 30 years. Majority of the study population were $69.3 \%$ Primi gravidas. Out of 130 cases, $56.2 \%$ were grade 2 meconium stained liquor, $30.7 \%$ were grade 3 meconium stained and $13.1 \%$ were grade 1 meconium stained. Association between neonatal complications in relation to grades of meconium was found to be statistically significant $(\mathrm{p}=0.001)$. NICU admission was $24.7 \%$ in grade 2 meconium group. Hypoxic Ischemic encephalopathy was high in grade 3 meconium group, 45\%. Majority of babies born through grade 1 meconium were asymptomatic and 10\% of babies in grade 3 meconium groups were asymptomatic. Meconium aspiration syndrome, Respiratory distress were more in babies born through deliveries complicated with grade 3 meconium.

Conclusions: The study indicated meconium stained amniotic fluid during labour increases the prevalence of abnormal intrapartum CTG, Caesarean section, lower Apgar score, increased duration of NICU and hospital stay, poor perinatal outcome and non-significant difference in incidence of lower birth weight in babies.
\end{abstract}

Keywords: Maternal risk factor, Meconium staining of amniotic fluid, Pregnancy

\section{INTRODUCTION}

Amniotic fluid is the product of complex and dynamic fetal and placental physiologic process. Amniotic fluid is vital to the well-being of the fetus. It cushions the fetus from injury, helps prevent compression of the umbilical cord and gives room for the fetus to move and grow. ${ }^{1}$
Meconium is the first intestinal secretion from fetus. Meconium staining of amniotic fluid (MSAF) is regarded as a sign of fetal distress and fetal asphyxia. Although exact cause is unknown, meconium is thought to be passed from fetal gastro- intestinal tract as a response to hypoxia, mesenteric vasoconstriction induced gut hyper peristalsis, falling umbilical venous saturation, vagal 
stimulation and normal physiologic function of mature fetus. Meconium aspiration syndrome (MAS) occurs in nearly $35 \%$ of live births with meconium stained liquor (MSL). Aspiration of meconium into the fetal or neonatal respiratory tract is associated with mild to severe respiratory compromise and increased perinatal mortality and morbidity. Thus, this study helps in observing the perinatal outcome in deliveries complicated with meconium stained liquor. ${ }^{2}$ Maternal factors can be hypertension, gestational diabetes, chronic respiratory, cardiovascular disease, past dated pregnancy, prolonged labour. Fetal factors can be cord problems, placental problems, and fetal distress. ${ }^{3}$ Fetus pass meconium in $10 \%$ of all pregnancies, in $5 \%$ of these; meconium is aspirated into the lungs of the fetus or neonate. This can result in severe respiratory distress, MAS which increase in the case of non-reassuring fetal heart rate (FHR) and remains relatively common cause of perinatal morbidity and mortality because it is difficult to prevent it. ${ }^{4}$ Rates of severe mental retardation and cerebral palsy are significantly high among infants born with MSAF. In the past two decades attention has been focused on the need for strengthening newborn care at primary care level. This study is done to identify predictors of MSAF. ${ }^{5}$ MSAF is common in term births especially in past dated pregnancies. While the more advanced maturation process of gastrointestinal tract may account for the higher rate of MSAF in past date, it is generally believed that the presence of MSAF in other circumstances is a marker of fetal distress. ${ }^{6}$ A relationship with stillborn infants, abnormal fetal heart rate tracings, neonatal encephalopathy, respiratory distress and abnormal neurologic outcome has been reported in literature. ${ }^{7,8}$ Meconium stained infants have low scalp blood $\mathrm{pH}$ and low umbilical artery pH. ${ }^{9}$ Additionally these babies have lower Apgar score in the first and fifth minute after delivery. ${ }^{10}$ The aim of the study was associated with the prevalence of various maternal risk factors associated with meconium stained amniotic fluid.

\section{METHODS}

This is a cross sectional study done at Government Medical College, Thrissur on term, singleton pregnancies complicated with meconium stained amniotic fluid satisfying the inclusion criteria. The cases were studied during a period from January 2016 to December 2016. Socioeconomic stratification was done into APL and BPL according to the entry in the ration card provided by the State Government. Term labour (>37 completed weeks), Cephalic presentation and Live singleton pregnancy were included in the study. Womens with Antepartum haemorrhage, Malpresentations, pregnancy with congenital malformations, intrauterine death, multiple pregnancies, and pregnancy with previous LSCS, severe pre-eclampsia and IUGR were excluded in the study.

Sample size: A total of patients calculated from the formula:
$4 \mathrm{PQ} / \mathrm{D}^{2}=4 \times 1.5 \times 98.5 / 2 \times 2=130$

$\mathrm{Q}$ is $100-\mathrm{P}, \mathrm{D}$ is difference between sample and control group value on the variable measured, $\mathrm{P}$ is average of sample and control group values on the smallest value of variable measured.

\section{Study Design}

Patients detailed history, gestational age, per abdominal examination, per speculum and per vaginal examination, admission tests including intrapartum cardiotocography (CTG) was recorded in a predesigned proforma. Patients with meconium stained liquor detected during artificial rupture of membranes or presenting with leaking per vaginum was closely observed for the essence of the study. The fetal heart rate tracing is classified as normal, suspicious, abnormal according to NICE (National Institute of Clinical Excellence) guidelines. ${ }^{11}$ Meconium staining of amniotic fluid was classified as Grade I, II, and III by visual examination, after spontaneous or artificial rupture of membranes. Grade I is translucent, light yellow green colour, grade II MSL is opalescent with deep green and light yellow in colour Grade III is opaque and deep green in colour. A fetal heart rate abnormality was detected and was done by safest mode of delivery either by normal vaginal delivery or instrumental vaginal delivery or caesarean section. All patients underwent full trial of labour and caesarean section was done only when trial becomes unsuccessful or if there were obstetric or fetal indications like fetal distress. The APGAR score of neonates at 5 minutes, birth weight, neonates who have meconium aspiration syndrome, Neonatal Intensive Care Unit (NICU) admission, babies with birth asphyxia was recorded. After finding mode of delivery, association of fetal birth weight and grades of meconium stained liquor was found out along with neonatal outcome in different grades of meconium stained liquor. The patients was carefully watched for progress of labour and strictly monitored for fetal heart rates by doing intermittent auscultations. Presence of meconium after spontaneous or artificial rupture of membranes was followed by cardiotocography for $20 \mathrm{~min}$ and then mode of delivery was decided after considering all obstetric conditions. Amnio infusion was given on noticing meconium after spontaneous or artificial rupture of membranes. After the delivery, authors studied the perinatal outcome in meconium stained amniotic fluid and distribution of complications among different grades of meconium. The babies in the above situations were followed up till discharge.

\section{Statistical Analysis}

All the relevant data is collected as per proforma and tabulated in Microsoft Excel and was analysed using statistical software and chi square test applied between the different associations above mentioned. 95\% confidence interval, association of each variable with grades of meconium is calculated. If the $\mathrm{p}$ value $<0.05$, it 
was considered as significant. Analysis of data was done using appropriate statistical software like SPSS.

\section{RESULTS}

The age of the patients varied between above 19 and 30 years. Majority of the study population belonged to age group between 20 and 25 years was $41.5 \%$ (Figure 1).

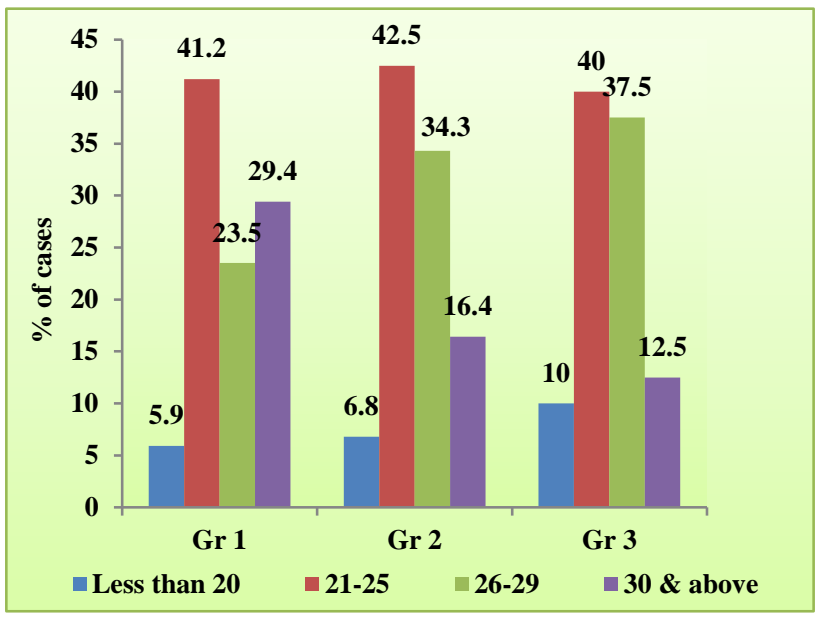

Figure 1: Age distribution in percentage with grades of meconium.

Majority of the study population were $69.3 \%$ Primi gravidas (Table 1).

Table 1: Distribution of gravidity among MSAF.

\begin{tabular}{|lll|}
\hline Gravidity & Count & Percent \\
\hline Primi & 90 & 69.3 \\
\hline Gravida 2 & 31 & 23.8 \\
\hline Gr. 3 and above & 9 & 6.9 \\
\hline
\end{tabular}

Out of 130 cases, $56.2 \%$ were grade 2 meconium stained liquor, $30.7 \%$ were grade 3 meconium stained and $13.1 \%$ were grade 1 meconium stained (Figure 2).



Figure 2: Distribution of different grades of meconium.

There were $9.2 \%$ of the cases associated with hypertension, $9.2 \%$ of the patients had gestational diabetes (GDM), 9.2\% had hypothyroidism and $6.9 \%$ were treated for infertility. Majority of the patients with meconium stained liquor had induced labour, 56.2\% (Table 2)

Table 2: Mechanism of labour.

\begin{tabular}{|lll|}
\hline Mechanism of labour & Count & Percent \\
\hline Induced & 73 & 56.2 \\
\hline Spontaneous & 56 & 43.0 \\
\hline
\end{tabular}

Out of 130 cases $43.8 \%$ cases each of meconium staining was noticed during artificial rupture of membranes (ARM) and spontaneous onset during the process of labour. $12.4 \%$ of patients presented with premature rupture of membranes with meconium (Table 3 ).

Table 3: Timing of meconium detection.

\begin{tabular}{|lll|}
\hline Meconium detection & No. of cases & $\%$ \\
\hline Spontaneous & 57 & 43.8 \\
\hline During ARM & 57 & 43.8 \\
\hline PROM & 16 & 12.4 \\
\hline
\end{tabular}

Babies with cord around the neck once had $16.9 \%$ and $3.1 \%$ had cord around neck twice. 58.5\% Patients had normal CTG. $22.3 \%$ patients had decreased variability in CTG intrapartum. $19.2 \%$ patients had prolonged deceleration in CTG intrapartum. Distribution of intrapartum CTG among the study group after detection of meconium (Figure 3 ).

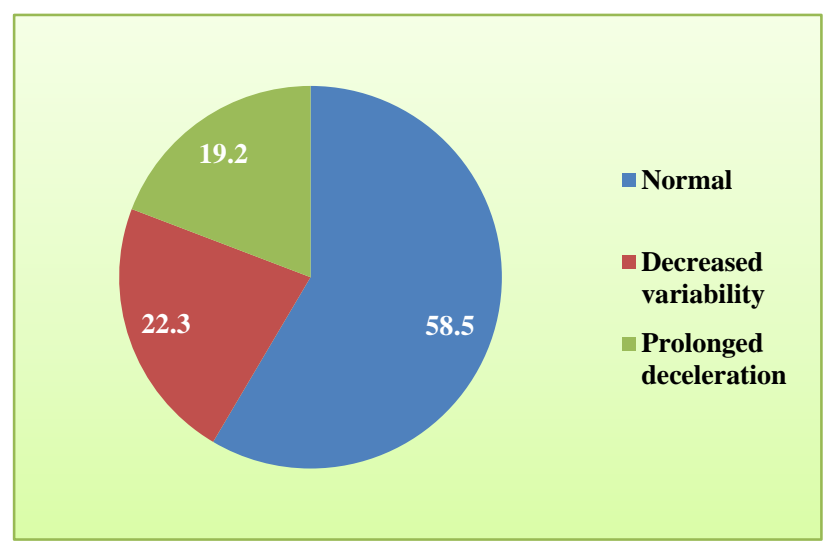

Figure 3: Distribution of intrapartum CTG.

Among 130 deliveries complicated with meconium stained liquor, $55.4 \%$ had prolonged duration of labour. 50 percent of women in the study group with labour complicated with meconium underwent cesarean section and $45.6 \%$ underwent normal vaginal delivery and 4.6 percent had instrumental delivery.

Among 40 cases of grade 3 meconium, majority of patients had cesarean delivery and majority of grade 1 and grade 2 meconium had vaginal delivery. There was statistically significant association between grades of meconium and mode of delivery, $\mathrm{p}=0.008$ (Table 4 ). 
Table 4: Relation between grades of meconium and mode of delivery.

\begin{tabular}{|llllll|}
\hline $\begin{array}{l}\text { Mode of } \\
\text { delivery }\end{array}$ & & Gr 1 & Gr 2 & Gr 3 & Total \\
\hline Vaginal & Count & 11 & 38 & 10 & 59 \\
delivery & Percent & 64.7 & 52.1 & 25.0 & 45.4 \\
\hline $\begin{array}{l}\text { Caesarean } \\
\text { section }\end{array}$ & Count & 6 & 30 & 29 & 65 \\
\cline { 2 - 5 } $\begin{array}{l}\text { Instrumental } \\
\text { delivery }\end{array}$ & Percent & 35.3 & 41.1 & 72.5 & 50.0 \\
\cline { 2 - 5 } & Percent & 0 & 5 & 1 & 6 \\
\hline$\chi^{2}=13.68, P=0.008$ & & & 2.5 & 4.6 \\
\hline
\end{tabular}

$\chi^{2}=13.68, \mathrm{P}=0.008$

Majority of cesarean section were due to fetal distress following meconium passage in labour, 24.6\%. Nonreassuring CTG was present in $5.4 \%$ cases. Among 130 deliveries complicated with meconium stained liquor, in $26.2 \%$ cases babies had respiratory distress and $16.2 \%$ had hypoxic ischemic encephalopathy (HIE). In $33.1 \%$ cases, babies were asymptomatic and in $19.1 \%$ babies had NICU admission. Meconium aspiration syndrome occurred in $5.4 \%$ babies. The mean birth weight of babies in grade 1 meconium group is $2.29 \pm 0.69$. Mean birth weight in grade 2 meconium group is $2.26 \pm 0.76$. The mean birth weight of grade 3 meconium group is $2.2 \pm 0.82$ which was lower than the other two groups. Relation between birth weight and different grades of meconium was not statistically significant. $(\mathrm{p}=0.89)$.

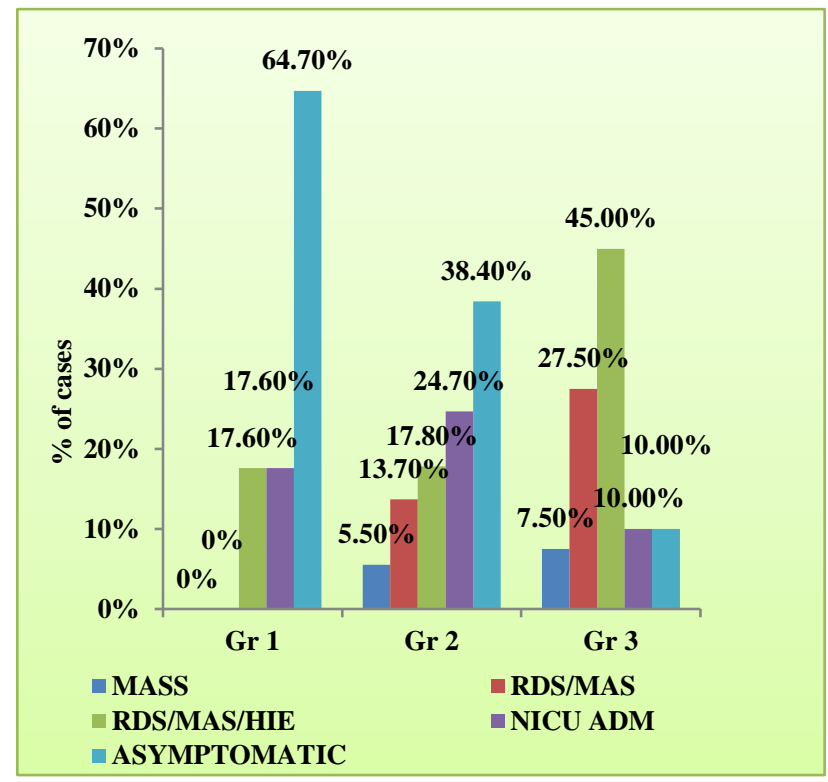

Figure 4: Distribution of neonatal complications among different grades of meconium group.

The mean birth weight in the study group was found to be $2.25 \pm 0.77$. The mean duration of stay of babies in NICU was 3.6 \pm 2.9 days and Mean duration of stay of babies in hospital was $5.8 \pm 4.7$ days. $82.2 \%$ of babies with grade 2 meconium had Apgar score of 7-8 but babies born through grade 3 meconium had lower Apgar score at 5 minutes of less than 7 . No babies born through grade 3 meconium had Apgar score 9. There was a significant association between higher grade of meconium and lower Apgar score at 5 minutes after birth $(\mathrm{p}=0.001)$. Mean duration of hospital stay of babies born through grade 3 meconium was $7.98 \pm 4.28$ days and $5.19 \pm 4.6$ in grade 2 meconium group. There was statistically significant association between higher grades of meconium and increased duration of hospital stay $(\mathrm{p}=0.001)$. There was a statistically significant increased duration of intensive care unit stay for babies born through grade 3 meconium.

Association between neonatal complications in relation to grades of meconium was found to be statistically significant $(\mathrm{p}=0.001)$. NICU admission was $24.7 \%$ in grade 2 meconium group (Figure 4). HIE was high in grade 3 meconium group, $45 \%$ as shown in Figure 5.

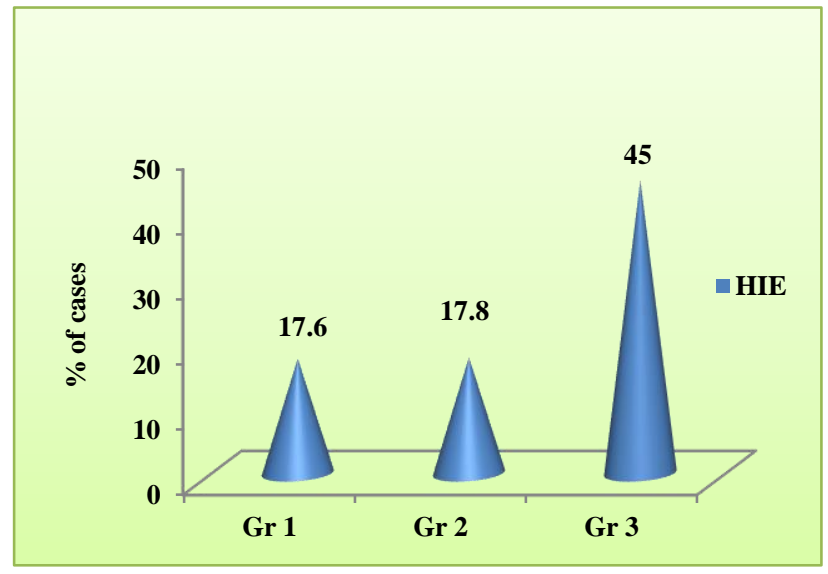

Figure 5: Distribution of incidence of HIE among different grades of meconium group.

Majority of babies born through grade 1 meconium were asymptomatic and $10 \%$ of babies in grade 3 meconium groups were asymptomatic. MAS were more in babies born through deliveries complicated with grade 3 meconium (Figure 6).

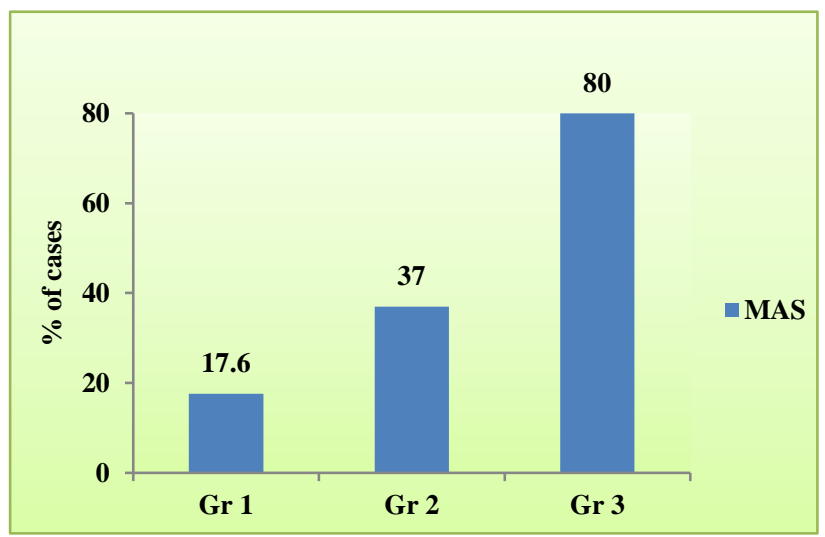

Figure 6: Distribution of MAS among different grades of meconium group.

As shown in Figure 7, Respiratory distress (RDS) were also more in babies complicated with grade 3 meconium born through deliveries. 


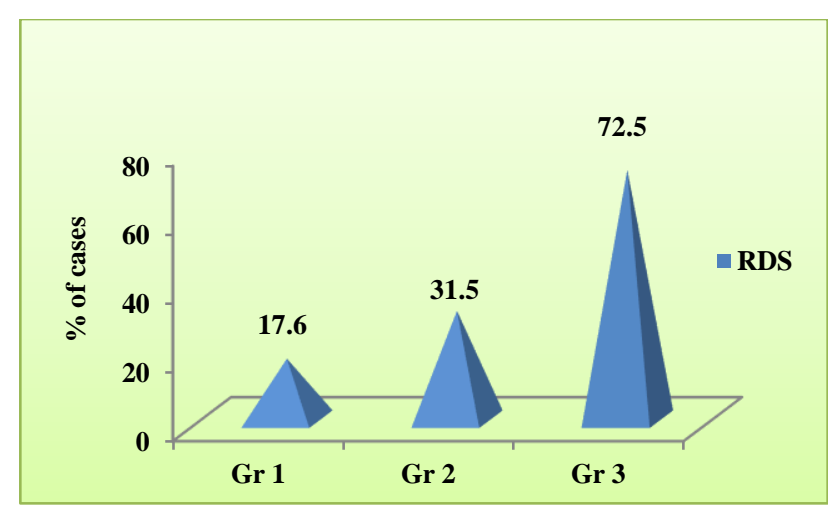

Figure 7: Distribution of RDS among the different grades of meconium group.

\section{DISCUSSION}

The present study was carried to identify the maternal risk factors associated and perinatal outcome in deliveries complicated with meconium stained amniotic fluid. Maternal risk factors are described as per pre-designed proforma based on antenatal complications requiring antepartum fetal surveillance. Risk factors and perinatal outcome are compared with different grades of meconium. The booking status and socioeconomic status of the patients does not show much difference among grades of meconium. Majority of the cases belong to below poverty line category. This can be due to the fact that present institution caters to the need of the low privileged strata of the society. Incidence of MSAF among 1800 deliveries conducted during the study period was $6 \%$. Among which $56.2 \%$ cases were grade 2 meconium stained, $30.7 \%$ were grade 3 meconium stained and $17 \%$ grade 1 meconium stained liquor. There were $69.3 \%$ primigravidas. Past dated pregnancies were found to be more associated with meconium stained liquor.

In a study by Majeed E in 2007 incidence of meconium stained amniotic fluid in past dated pregnancies was $16 \% .^{12}$ In this study, the incidence of past date is $15.3 \%$ comparable to the other studies. The $9.2 \%$ cases were complicated with hypertensive disorders. It is comparable to Sundaram R study where incidence of hypertension was $14 \% . .^{13}$ Also, 9.2\% had GDM and hypothyroid disorder. The frequency of MSAF increased with advanced gestational age at delivery. In past date $15.3 \%$ was meconium stained liquor in labour. Naveen et al conducted a study on 1500 deliveries to identify the predictors of MSAF and observed that past date was one of the significant risk factors. ${ }^{14}$ However, 56.2\% had induced labour, but the association between mechanism of labour and incidence of meconium stained liquor was not statistically significant. Similar relation was found by Gali et al where induced labour was statistically significant $(p=0.01)$ in meconium group and the relation. ${ }^{15}$ Furthermore, $50 \%$ delivered by Cesarean section, $45.4 \%$ delivered normally and $4.6 \%$ had instrumental delivery.
Study by Sharma et al $56 \%$ delivered by Cesarean section, $20 \%$ delivered normally and $24 \%$ had instrumental delivery. ${ }^{16}$ The incidence of operative intervention was significantly increased in the present study $(p=0.008)$. There were 13 cases of perinatal mortality in the present study. In a study by Mundhra et al perinatal mortality was 15,8 due to birth asphyxia, 4 cases due to HIE and 2 case due to respiratory distress and respiratory failure and 1 due to septicemia following meconium aspiration syndrome. ${ }^{6}$ The incidence of meconium aspiration syndrome in the present study was found to be $5.4 \%$. Risk factors for meconium stained liquor in the present study $24.7 \%$ had premature rupture of membranes. Prolonged labour is a risk factor for meconium passage. In the present study $55.3 \%$ had prolonged labour. Naveen et al found a similar association between prolonged labour and meconium passage in labour. ${ }^{14}$ Bansal et al reported that meconium stained amniotic fluid is significantly more in deliveries complicated with fetal distress. ${ }^{17}$ In the present study $24.6 \%$ cases were complicated with fetal distress. Apgar score at 5 minutes was significantly lower in babies born through meconium stained liquor which is comparable to Mundhra et al study. ${ }^{6}$ Infants with low Apgar scores and $21.21 \%$ needed intensive care admission. In a study by Mundhra et al, 20\% babies had low Apgar score and the association was significant $(p=0.0002) .{ }^{6}$ On the other hand, Babies with MSAF had lower Apgar scores and in the present study had NICU admission which is comparable to Parveen et al where the incidence was $21.2 \%$. Majeed E et al found an incidence of $18.8 \%$ for MAS in the thick meconium group and $28.4 \%$ in a study by Mundhra et al. ${ }^{6,12}$ The study shows that perinatal asphyxia with HIE was seen in $26.2 \%$ and the association with grade 3 meconium was statistically significant $(\mathrm{p}=$ 0.001) which accordance with Shazia et al found out HIE in $11.1 \% .^{18}$ Thus, it is clear that the consistency of meconium have a significant effect on perinatal outcome. Grade 3 meconium group babies have lower Apgar scores, high association with meconium aspiration and perinatal mortality.

\section{CONCLUSION}

The study concluded that presence of meconium stained amniotic fluid during labour increases the prevalence of abnormal intrapartum CTG, Caesarean section, lower Apgar score, increased duration of NICU and hospital stay, poor perinatal outcome and non-significant difference in incidence of lower birth weight in babies. Maternal factors were significant risk factors and past dated pregnancies, induced mechanism of labour and prolonged duration of labors were none significantly associated with meconium stained amniotic fluid. Meconium stained amniotic fluid detection is associated with higher incidence of operative delivery resulting in increased maternal morbidity. It is also associated with an increased neonatal morbidity due to birth asphyxia and respiratory depression at birth and an increased risk of neonatal mortality due to meconium aspiration syndrome. 


\section{ACKNOWLEDGMENTS}

Authors are thankful to the Department of Obstetrics and Gynaecology, Thrissur for their cooperation and support and to all the patients without whom this study might not have been materialised.

Funding: No funding sources Conflict of interest: None declared

Ethical approval: The study was approved by the Institutional Ethics Committee

\section{REFERENCES}

1. Oyelese Y. Placenta, umbilical cord and amniotic fluid: the not-less-important accessories. Clinical Obstet Gynecol. 2012;55(1):307-23.

2. Yurdakok M. Meconium aspiration syndrome: do we know?. Turkish J Pediatr. 2011;53(2):121-9.

3. Gongora MC, Wenger NK. Cardiovascular Complications of Pregnancy. Int $\mathrm{J}$ Mol Sci. 2015;16(10):23905-28.

4. Lee J, Romero R, Lee KA, Kim EN, Korzeniewski SJ, Chaemsaithong $\mathrm{P}$, et al. Meconium aspiration syndrome: a role for fetal systemic inflammation. Am J Obstet Gynecol. 2016;214(3):366-e1.

5. Afsar S, Motwani NP, Sudhakar C, Chaturvedi U. Evaluation of neuro-developmental outcome among babies with meconium aspiration syndrome. Int $\mathbf{J}$ Contemp Pediatr. 2016;3(4):1185-8.

6. Mundhra R, Agarwal M. Fetal outcome in meconium stained deliveries. J Clinical Diagnost Res: JCDR. 2013;7(12):2874-6.

7. Galal M, Symonds I, Murray H, Petraglia F, Smith R. Postterm pregnancy. Facts Views Vis Obgyn. 2012;4(3):175-87.

8. Caughey AB, Snegovskikh VV, Norwitz ER. Postterm pregnancy: how can we improve outcomes? Obstet Gynecol Survey. 2008;63(11):715-24.

9. Boujenah J, Oliveira J, De La Hosseraye C, Benbara A, Tigaizin A, Bricou A, et al. Should fetal scalp blood sampling be performed in the case of meconium-stained amniotic fluid?. J Mat-Fet Neonat Med. 2016;29(23):3875-8.
10. Persson M, Razaz N, Tedroff K, Joseph KS, Cnattingius S. Five and 10 minute Apgar scores and risks of cerebral palsy and epilepsy: population based cohort study in Sweden. BMJ. 2018;360:k207.

11. Sakoda A, Ikuma S, Baba M, Sato M, Sumikura H. Review of 197 cases of urgent cesarean section performed in 2010 using NICE classification. Masui. Japanese J Anesthesiol. 2014;63(12):1339-43.

12. Shaikh EM, Mehmood S, Shaikh MA. Neonatal outcome in meconium stained amniotic fluid-one year experience. JPMA The Journal of the Pakistan Medical Association. 2010;60(9):711-4.

13. Sundaram R, Murugesan A. Risk factors for meconium stained amniotic fluid and its implications. Int J Reprod Contracept Obstet Gynecol. 2017;5(8):2503-6.

14. Naveen S, Kumar SV, Ritu S, Kushia P. Predictors of meconium stained amniotic fluid: a possible strategy to reduce neonatal morbidity and mortality. $\mathbf{J}$ Obstet Gynecol India. 2006;56(6):514-7.

15. Pariente G, Peles C, Perri ZH, Baumfeld Y, Mastrolia SA, Koifman A, et al. Meconium-stained amniotic fluid-risk factors and immediate perinatal outcomes among SGA infants. J Mat-Fet Neonat Med. 2015;28(9):1064-7.

16. Sharma U, Garg S, Tiwari K, Hans PS, Kumar B. Perinatal outcome in meconium stained amniotic fluid. J Evol Med Dent Sci. 2015;48:8319-27.

17. Bansal N, Gupta V, Nanda A, Chaudhary P, Tandon A, Behl N. Intrapartum amnioinfusion in meconiumstained liquor: a case-control study. J Obstet Gynaecol India. 2013;63(3):164-7.

18. Qadir S, Jan S, Chachoo JA, Parveen S. Perinatal and neonatal outcome in meconium stained amniotic fluid. Int J Reprod Contracept Obstet Gynecol. 2017;5(5):1400-5.

Cite this article as: Mohan M, Deepak AV. Maternal risk factors and perinatal outcome in meconium stained amniotic fluid: a cross sectional study. Int J Reprod Contracept Obstet Gynecol 2018;7:4103-8. 